the technical route and index to be closely related to the research goal and the research content. Operable, can demonstrate the problems to be studied. This study focuses on the therapeutic effect of acupuncture combined with laser on the treatment of allergic rhinitis, and it will provide a scientific basis for the clinical treatment of allergic rhinitis, which has broad application foreground and academic value.

Materials and methods 60 patients with allergic rhinitis were divided into acupuncture combined with laser group and western medicine control group according to the principle of randomized openness. Thirty patients were treated with acupuncture combined with laser group, acupoints: Yintang, (Selected by the Beijing Tianxingjian Medical Technology Co., Ltd., APOTREAT-800 series of ultrasound, laser, neuromuscular electrical stimulation system in the laser system), the combination of nasal cavity laser, , Acupuncture for 1 / day, 30min / time, nasal laser treatment 2 times / day, 30min / times, between the two treatment interval of 3 hours or more, continuous treatment for 10 days, 10 days for a course of treatment; Western medicine control Group of 30 cases, the choice of interest Si Min, (common name: loratadine tablets), the Chinese medicine Zhunzi H20070030, Xi'an Yansen Pharmaceutical Co., Ltd., 1 / day, 1 / times, continuous oral 10 days, 10 days 1 Treatment.

After a course of treatment, the observed indicators were evaluated.

Results and discussion There was no significant difference between the two groups in terms of age, sex, duration, condition and other general data.

Acupuncture combined with laser group was significantly better than Western medicine control group, acupuncture combined with laser treatment of allergic rhinitis efficacy.

Address: Nangang District, Harbin Gogol Street 411, acupuncture five wards E-mail: shanshan20072151@163.com

UDK 616.24-002-07-08 (571-6) DOI 10.22448/AMJ.2017.3.42-43

\title{
THE OUTCOMES OF THE TREATMENT OF SERIOUS COMMUNITY-ACQUIRED PNEUMONIA IN THE CONDITIONS OF MASS IMMUNIZATION BY THE GRIPPE VACCINE
}

\author{
Kruglyakova L.V., Naryshkina S.V., Sulima M.V. \\ FSBEI HE "Amur state medical academy" MH RF
}

Because of the high lethality the serious form of community - acquired pneumonia (SCAP) is one of the most dangerous diseases of organs of respiratory system. Aneffective treatment of SCAP is possible only in a case of timely made diagnose, adequate estimation of the severity of the patient's state which is the definite indicator to the hospitalization into the department of intensive therapy or into the department of reanimathology and anaesthesiology (DITR), timely and correct therapy, rational choose of antibacterial drugs (UBD) according to the main cause of the disease. The presence of the respiratory insufficiency, serious sepsis or septic shock andalso the spreading of pulmonary infiltrates are the main symptoms of SCAP. The rate of SCAP, underwent treatment and outcomes of this disease for the last three years (2014-2016) in specialized department of city clinical hospital were studied by the authors. The diagnose of SCAP was made according to clinical, rentgenologycal and microbiologycal criteria, reported in the instructions on diagnostic and treatment of SCAP [1, 2 ]. Statistic analysis was made with the help of automatic system [3, 4].

It is known, that lethality in SCAP remains high $[5,6,7]$ and regulary is getting higher in the period of seasonal sickness rate of grippe. In Amur Region annual mass grippe vaccination is usually performed in autumnal period. Only in 2016 it was possible to immunize almost half of adult population of the region against grippe and improve the outcomes of CAP. According to this date the authors studied the dinamics of hospitalization, peculiarities of clinical manifestations and outcomes of SCAP in the conditions of mass grippe immunization. There were also studied the dates of the addressing for medical help, the degree of severity of the case in admission to the hospital, accompanying pathology, the age of the patients and correct treatment of patients with SCAP in the hospital in comparisson aspect: in the years with insufficient immunized layer of adult population (2014- 2015) and 2016, when it was possible to immunaze $45,3 \%$ of population of Amur Region on the whole and $50.1 \%$ of population of Blagoveshchensk.

Analysis of the results of the treatment of patients with SCAP in pulmonology department of SAIH AR "Blagoveshchensk city clinical hospital" allowed to reveal the following regularities: the condition of higher immune layer of adult population there is the reduction of CAP cases, but at the same time the number of persons with SCAP still remains high enough. There is the mark of distinct trend to the reduction of death rate in hospital from CAP on the whole-from 2,98\% in 2014, to $2,39 \%$ ( $p>0,05, \chi=0,957)$. Death rate from SCAP was reduced from $25,5 \%$ in 2014, to $12,44 \%$ in $2016(p<0,001, \chi=7,93$ ).

Accordingtoauthorsopinion theseresultsareduetothecreating ofimmunizedlayer ofadultpopulation of the Amur Region in 2016 which is enough for the prevention of epidemic situation, introducing the standarts of specialized medical help into pulmonary department based on modern recommendations on SCAP treatment taking into consideration the proposed of etymological factor of the disease, timely treatment the states which complicate the duration of SCAP: bacterial shock, intoxicational syndrome, poliorganic insufficientia, respiratory insufficientia. As a result of performed prophylactic measures it was possible to reduce the number of patient with pneumonia in $26 \%$, lethelity from SCAP was reduced two times.

Literature: 
1. Demko I.V., Chubarova S.V., Gordeeva N.V. et al. Algorithms of diagnostics and records of proceedings of medical help in pneumonia. Methodic recommendations for physicians. - M. 2015. 49 c.

2. Intensive therapy in pulmonology (S.N. Avdeeva). V. 1. - 2014 - M. - "Atmosphera" - Serious community-acquired pneumonia $-249-270$.

3. The use of discriminative analysis in the development of diagnostic (prognostic) important rule / N.V. Ulyanychev, V.F. Ulyanycheva, V.P. Kolosov, Yu. M. Perelman// Informatics and systems of management. - 2009. - 4-13-15.

4. Kolosov V.P., Perelman Yu.M, Ulyanychev N.V. Methodologycal approaches to the development of thechnologies of prognosis in pulmonology // Bul. Physiol. and pathol of respiration 2006. 22. - 20-23.

5. Kruglyakova L.V., Naryshkina S.V., Orlova T.S.,Vjunova E.V. Hospital medical help and outcomes of community-acquired pneumonia in Blagoveshchensk- Materials of the VI Committee of physicions-pulmonologysts of Siberia and Far East. Blagoveshchensk. - $2015-110-114$.

6. Kruglyakova L.V., Naryshkina S.V.,Sulima M.V. Peculiarities of community-acquired pneumonia in Blagoveshchensk.- XXVI National Congress on the diseases of organs of respiration.- M. - $2016-96$.

7. Kruglyakova L.V., Markova E.G., Vjunova E.V., Pogorelova E.L. Criteria of diagnose of community-acquired pneumonia. XXVI National Congress on the diseases of organs of respiration -M. 2016. $97-98$.

UDC 619 : 616 . 995 . 132 . 6(571 .61) DOI 10.22448/AMJ.2017.3.43-44 SPREADING OF TRICHINOSIS IN THE ARKHARINSKY DISTRICT OF THE AMUR REGION

\author{
L. A. Guba
}

Amur State Medical Academy, Blagoveshchensk, Russia

Introduction The Arkharinsky district in the area of 14,6 thousand squire kilometers occupies the far south-east of the Amur region in the river basin of Arkhara. In the north-west and west it borders on the Bureisky district, in the east and south-east - on the Khabarovsky territory, in the south-west and south the frontier passes through the Amur river. Warm, temperate and damp climate prevails. An average temperature of January is $-26,7^{\circ} \mathrm{C}$, of July $+20,7^{\circ} \mathrm{C}$. Deciduous or larch woods and flood-lands are situated in the valley of the Amur river. Difficult to traverse, dense, deciduous and cedar deciduous woods with underbrush and lianas sometimes pine forests are typical for low mountains.

Fauna is presented by brown bear, black bear, wolf, Manchurian deer, Japanese wild boar, lynx, otter, Manchurian hare, common field mouse, mandarin duck, white-naped and Japanese cranes, grey larva-eating bird, Indian cuckoo, tree wagtail, black wild duck, Amur and patterned sledge runners, Far-Eastern tree frog and many species of insects are typical. A family of carps prevails in rivers and lakes.

Agriculture is an economic profile of the district.

Key words: trichinella, infection, raccoon dogs

The objective: to study epizootology, epidemiology, diagnostics and prophylaxis of trichinosis in the Arkharinsky district.

Materials and methods

Researches were carried out by methods of a compressor trichinelloscopy and digestion of muscles tests in an artificial gastric juice. 24 cuts from a masseter, a tongue, crura of diaphragm, gastrocnemius muscles were taken. Each cut was as large as an oat grain. The cuts were placed on the glass bottom of a compressor, covered with the upper glass and examined under the microscope MBS-10. The muscles, examined by digestion with gastric juice, were crushed in a meat grinder or with scissors. The received forcemeat was placed on the mill sieve № 23, being in the device of Berman, and filled with warm fresh artificial gastric juice in the ratio $100 \mathrm{ml}$ of artificial gastric juice per $1 \mathrm{~g}$ of forcemeat. Gastric juice was prepared according to: $3 \%$ - pepsin per $0,5 \%$ solution of hydrochloric acid. Berman's filled device was placed in the thermostat adjusted to the temperature $38-39^{\circ} \mathrm{C}$. In half an hour the sieve in the device was stirred up. In an hour necessary amount of liquid was taken from the device, placed into the Petri's dish and examined under the microscope BMS-1.

Material for research was received from hunters, sanitary-and-epidemiologic establishments and individuals.

Results and discussion

Larvae of trichinellae were revealed in a raccoon dog, a red fox, a sable and a lynx. The maximum contamination in raccoon dogs makes up $33 \%$, in foxes $-27 \%$ and in sables $-12 \%$. The average intensity of invasion in raccoon dogs makes up 93 larvae in $1 \mathrm{~g}$ of gastrocnemius muscles, in red foxes -88 larvae in $1 \mathrm{~g}$ of gastrocnemius muscles, in a sable -176 larvae in $1 \mathrm{~g}$ of masseter, in a lynx - 1112 larvae in $1 \mathrm{~g}$ of masseter

Species of Trichinella native was revealed in all cases by using the method of keeping exposed to frost in deep freezer at the temperature $-18^{\circ} \mathrm{C}$ during a week. High frost-resistance of this trichinellae species may prove the fact that invasion in nature comes from corpse to an animal.

Corpses of animals contaminated with trichinellaemay be used as a food in the frozen form only. According to V.A. Britov it is observed in winter. 